\title{
Territorio y patrimonio arqueológico de la Sierra de Cádiz: un proyecto por concluir
}

Luis Cobos Rodríguez | arqueólogo y director de la empresa ARQ Heritage Innovation URL de la contribución <www.iaph.es/revistaph/index.php/revistaph/article/view/3738>

\section{RESUMEN}

Territorio y arqueología de la Sierra de Cádiz constituyen un tándem de excelentes recursos patrimoniales, y un demostrado campo de acción de los agentes sociales y económicos para desarrollar programas que generen valor añadido en la oferta cultural y turística. El proyecto más significativo comenzó hace ya veinte años, denominado ruta arqueológica de los Pueblos Blancos y más tarde museo-territorio de la Sierra de Cádiz, que no culminó su última fase de gestión por diversos motivos. Sin embargo, nuevas perspectivas y estrategias pueden recuperar esta iniciativa y conseguir superar los retos del pasado.

\section{Palabras clave}

Cádiz (Provincia) | Desarrollo socioeconómico | Gestión cultural | Patrimonio arqueológico | Patrimonio cultural | Sierra de Cádiz | Territorio | 


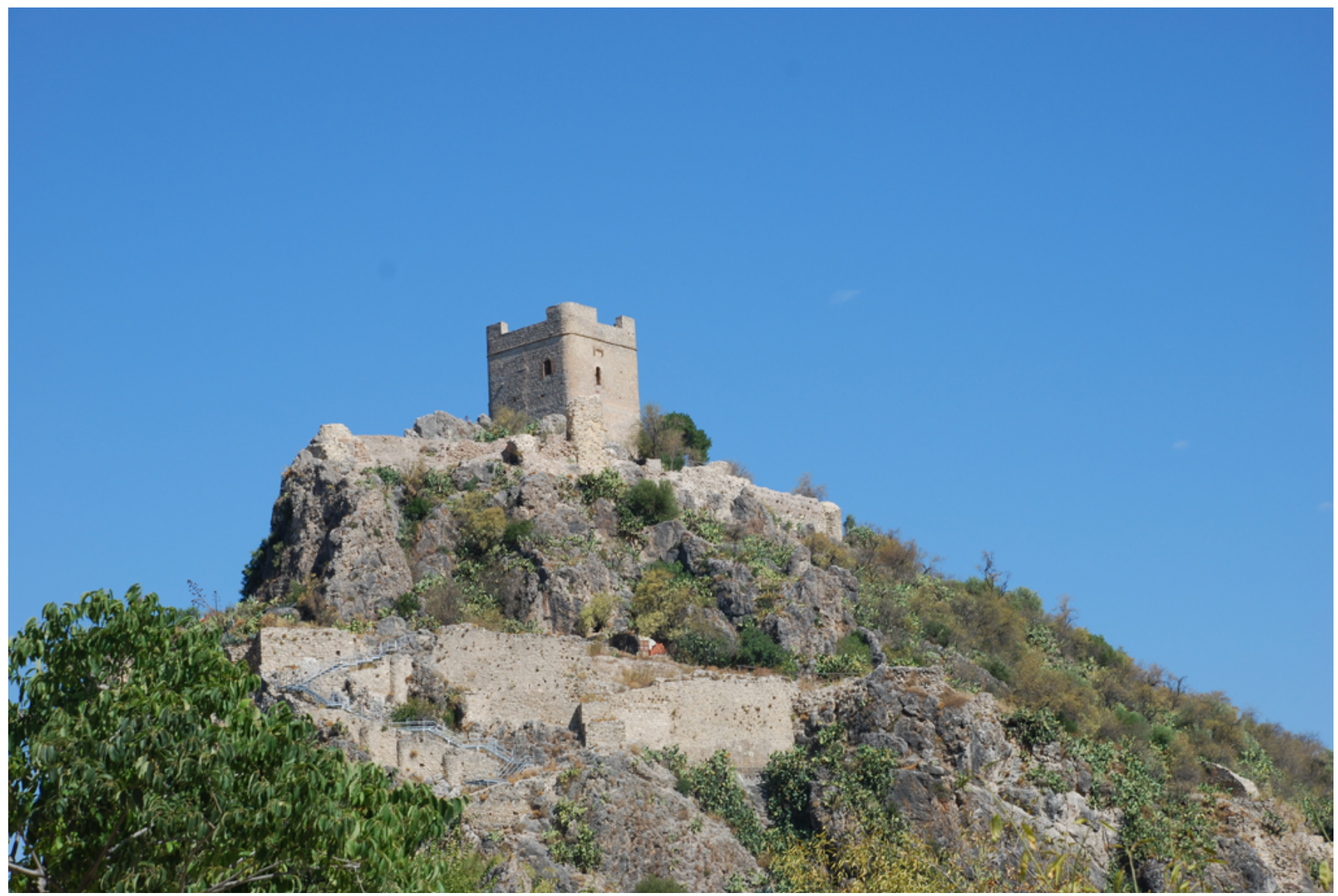

Villa medieval de Zahara de la Sierra | foto Luis Cobos 
En 1997 comenzó a construirse un proyecto de valorización del patrimonio arqueológico de la Sierra de Cádiz con el fin de dinamizar todo un territorio cultural y convertirlo en un auténtico museo al aire libre. Esta iniciativa, pionera en Andalucía en esos momentos, fue promovida por la Mancomunidad de Municipios de la Sierra de Cádiz y dirigida por los arqueólogos Luis J. Guerrero y el que escribe. Nuestro objetivo principal fue posicionar los recursos patrimoniales existentes para su explotación económica, su reconocimiento social y su uso cultural. Durante once años se trabajó para ello, con obstáculos y dificultades de todo tipo, hasta finalizar en 2007. La enrevesada gestión política del proyecto fue posiblemente la causa primordial de su finalización, sin embargo a día de hoy es factible recuperar la idea original, aprender de los fallos, pararse a pensar y ver con nuevas perspectivas y estrategias la recuperación de un proyecto que aún sigue vivo.

\section{PATRIMONIO TERRITORIAL}

Cuando hablamos de la Sierra de Cádiz desde el punto de vista territorial nos referimos a un espacio muy definido geográficamente que comprende un extenso territorio de más de dos mil kilómetros cuadrados, y que se sitúa en la parte nororiental de la provincia de Cádiz, lindando al norte con la provincia de Sevilla, al este con la de Málaga y al sur y al oeste con la comarca de la Campiña de Jerez. Aunque hablemos siempre de un territorio de sierra nos encontramos con una diversidad de realidades orográficas: por un lado, las zonas llanas de la campiña de la cuenca del Guadalete como continuación de la depresión del Guadalquivir (Arcos de la Frontera,

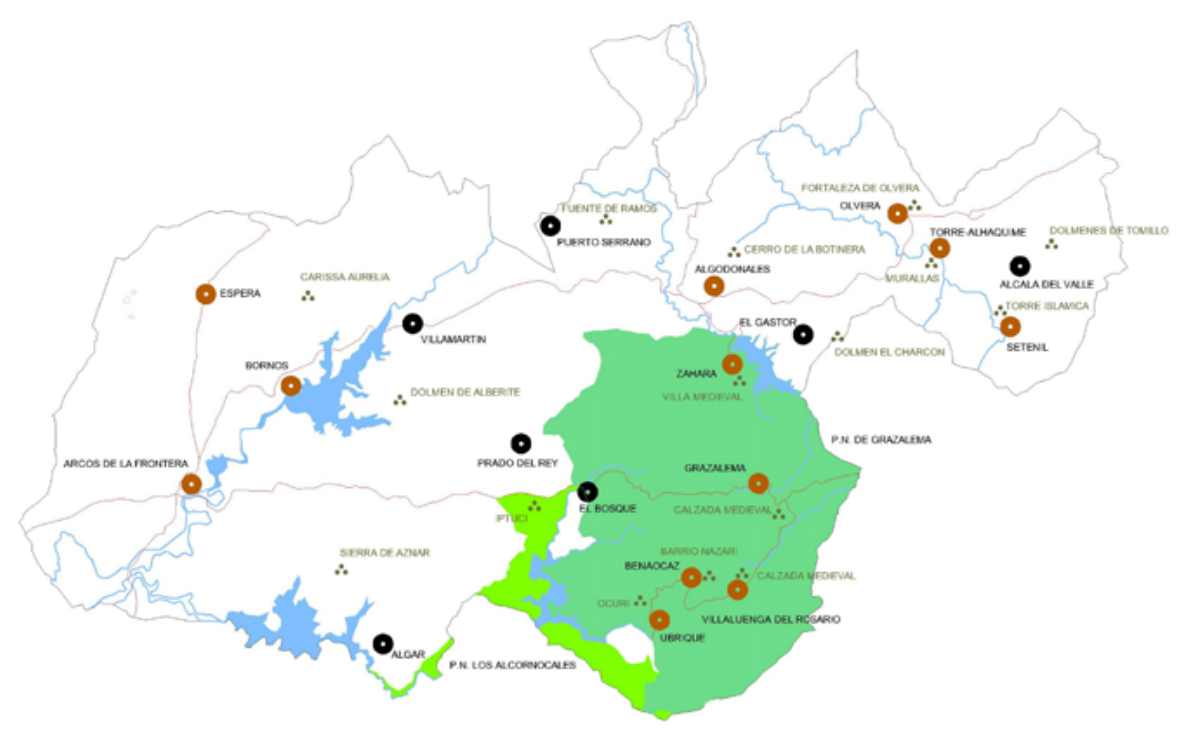

Sierra de Cádiz | mapa Consuelo Prados 
Bornos, Villamartín y Puerto Serrano); por otro, áreas más abruptas y con las elevaciones propias de la serranía que forman parte de la cordillera Bética, destacando en ella la sierra de Grazalema (El Bosque, Ubrique, Grazalema, Zahara de la Sierra, Ubrique, Benaocaz, El Gastor, Villaluenga del Rosario); y por último otras elevaciones de menor altura y valles interiores pertenecientes a la zona de las sierras Subbéticas (Algodonales, Olvera, Torre Alháquime, Setenil, Alcalá del Valle).

En este territorio es el río Guadalete el elemento aglutinador y unitario de la comarca que, además, sirve de nexo entre los diversos paisajes culturales, y que desde mediados del siglo XX modifica en parte el paisaje de la campiña con la construcción de los embalses de la cuenca: Arcos, Bornos y Zahara. Nace en Grazalema como río de montaña, con cauce estrecho y poco profundo, recibiendo aportes de otros cursos como el Gaidóvar, para después llegar a la campiña y recibir a su principal afluente, el Majaceite, también alterado por el embalse de Guadalcacín, configurando entre ambos los paisajes característicos de la Sierra de Cádiz (AA.VV., 1995: 29-37).

Contamos, además, con dos elementos de gran valor natural y cultural como son el Parque Natural de Grazalema (DECRETO 316/1984), con un paisaje kárstico de gran belleza paisajística; y el Parque Natural de los Alcornocales (LEY 2/1989), afectando, entre ambos, a los términos municipales de Grazalema, Zahara de la Sierra, El Bosque, Benaocaz, Villaluenga del Rosario, Ubrique, Prado del Rey, El Gastor, Arcos y Algar, ocupando un espacio de casi la mitad de la comarca. Otros espacios naturales protegidos son la Reserva Natural Complejo Endorréico de Espera, el Paraje Natural

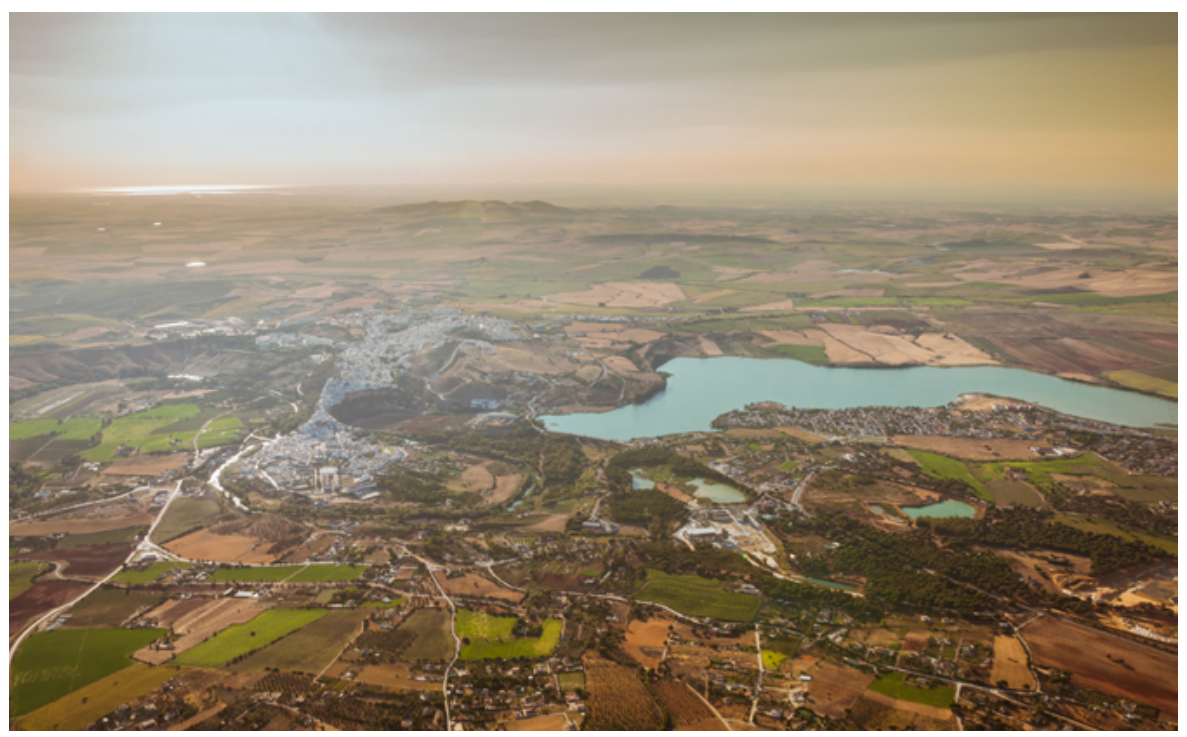

Campiña, el río Guadalete (embalse) a su paso por Arcos de la Frontera | foto Manu García 
1

Los conjuntos históricos BIC son Arcos de la Frontera, Algodonales, Benaocaz, Bornos, Espera, Grazalema, Olvera, Setenil, Torre Alháquime, Ubrique, Villaluenga del Rosario y Zahara de la Sierra.

\section{2}

La Ley $16 / 1985$, de Patrimonio Histórico Español de 25 de junio de 1985 señala en la Disposición Adicional Segunda que "Se consideran asimismo de Interés Cultural y quedan sometidos al régimen previsto en la presente Ley los bienes a que se contraen los Decretos de 22 de abrilde 1949, 571/1963 y 449/1973".
Cola del Embalse de Bornos, el Paraje Natural Cola del Embalse de Arcos de la Frontera y el Paraje Natural Peñón de Zaframagón.

Un total de 19 municipios, con una población cercana a los 120.000 habitantes pero con contrastes cuantitativos entre las diferentes poblaciones. La de mayor población está en zona de campiña (Arcos de la Frontera con 31.250 hab.) y la más baja en la serranía (Villaluenga del Rosario con 456 hab.). Posee la comarca 43 bienes de interés cultural $(11,19 \%$ de la provincia de Cádiz), de los cuales doce son conjuntos históricos declarados (CATÁLOGO, $2013)^{1}(63 \%$ de la comarca); otros dos son yacimientos arqueológicos (Iptuci y Carissa Aurelia) y todos los castillos y fortalezas, por el Decreto de 22 de abril de 1949 sobre Protección de Castillos Españoles, expedido por el Ministerio de Educación Nacional².

Por tanto, nos encontramos ante una serie de elementos naturales y otros de construcción humana que conforman un paisaje singular en constante evolución: ríos y embalses; vías de comunicación; campiñas, valles y sierras; parques, parajes y espacios naturales protegidos de gran valor medioambiental y ecológico; diecinueve localidades denominadas como Pueblos Blancos desde los años sesenta por el Ministerio de Turismo; un patrimonio cultural que incluye bienes inmuebles (iglesias, ermitas, monasterios, castillos, torres, fortalezas, pósitos, cillas, cortijos, molinos, santuarios, fuentes, lavaderos...), yacimientos arqueológicos, y una gastronomía, artesanía singular y un conjunto de prácticas, representaciones, expresiones, conocimientos y habilidades de su patrimonio intangible que le aporta una identidad propia $y$, por supuesto sus ciudadanos, verdaderos protagonista de su presente y futuro, y responsables de mantener su pasado.

Este es el presente del territorio de la Sierra de Cádiz, el contenedor a lo largo de la historia de un patrimonio cultural de indudable valor histórico, científico y simbólico, y de una potencialidad educativa y turística de gran alcance. Sin

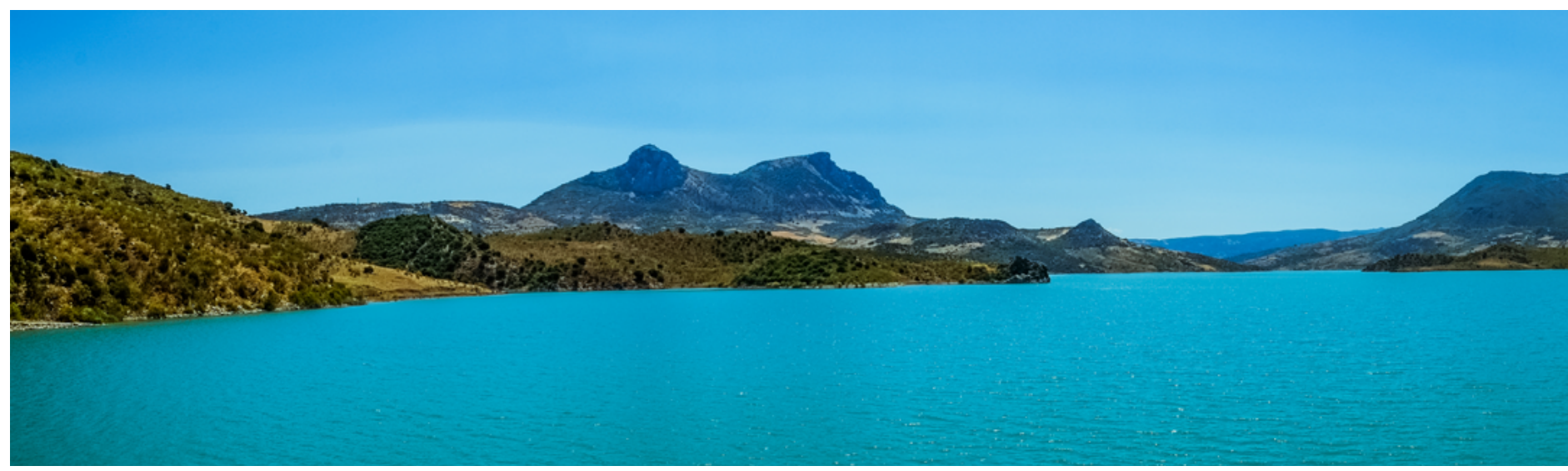


embargo, el territorio ha pasado de ser un simple escenario y soporte de un colectivo y de su patrimonio cultural a ser protagonista, a considerarse también como un recurso patrimonial, objeto de estudio de los investigadores y campo de acción de los agentes sociales y económicos, así como de las instituciones que dirigen y diseñan políticas culturales (CARAVACA BARROSO; FERNÁNDEZ SALINAS, 2005: 5-18). Un territorio amplio, disperso y que constituye un espacio donde se han desarrollado iniciativas patrimoniales, especialmente, en el patrimonio arqueológico.

\section{ANTECEDENTES}

En este territorio, y a través de políticas de fomento del empleo y de recuperación de bienes culturales y naturales, se han llevado a cabo una serie de proyectos, algunos inacabados, que podemos considerar vinculados a la intervención en el paisaje de la Sierra de Cádiz, desde una visión patrimonial y sobre todo desde la arqueología.

Una de las iniciativas de mayor envergadura y proyección fue la conocida ruta arqueológica de los Pueblos Blancos, desarrollada por la Mancomunidad de Municipios de la Sierra de Cádiz, donde el territorio pasó a ser de manera práctica un recurso patrimonial en sí, que sumado al patrimonio arqueológico constituyó una relevante actuación en el paisaje. Este proyecto que nace desde la arqueología se convirtió en una verdadera propuesta de intervención integral en el patrimonio cultural de la Sierra de Cádiz ${ }^{3}$.

Hasta mediados de los noventa las intervenciones arqueológicas se reducían a actuaciones puntuales en algunos de los yacimientos de la Sierra de Cádiz, sin ninguna o escasa proyección social. Es en 1993 cuando se inicia un proyecto general denominado Intervenciones en áreas de interés turístico cultural de la Sierra de Cádiz, promovido por el INEM, la Diputación de Cádiz
3

Iniciativa codirigida por Luis Javier Guerrero Misa y Luis Cobos Rodríguez.
Zahara, sierra del Pinar, monte Algarín y la cima de las Grajas | foto Manu García 
y la Consejería de Cultura de la Junta de Andalucía, en el que se incluían actuaciones de puesta en valor en algunos yacimientos arqueológicos, como la calzada romano-medieval de Ubrique a Benaocaz, la ciudad romana de Iptuci, la villa medieval de Zahara de la Sierra, entre otros bienes patrimoniales (COBOS RODRÍGUEZ, 2003: 10).

Poco tiempo después la Mancomunidad de Municipios de la Sierra de Cádiz apostó, desde mediados de 1996, por la aplicación de programas que tenían como objetivo la rentabilización social, económica y cultural de su rico patrimonio histórico y arqueológico. Estos programas se encuadraban en el ámbito de las nuevas políticas de empleo y desarrollo sostenible auspiciadas por la Unión Europea, en su incesante búsqueda de nuevos yacimientos de empleo. La denominación genérica de los mismos se enmarcó bajo el epígrafe de Recuperación y puesta en valor de los yacimientos arqueológicos de la Sierra de Cádiz (GUERRERO MISA; COBOS RODRÍGUEZ, 2002: 125). En estos momentos iniciales, el ámbito de actuación en la propia sierra se limitó a tan sólo cinco yacimientos arqueológicos claves, situados en otros tantos municipios serranos: Sierra Aznar en Arcos de la Frontera; la ciudad romana de Carissa Aurelia en Espera; la ciudad romana de Ocuri en Ubrique; el dolmen de Alberite en Villamartín; y la villa medieval de Zahara de la Sierra. En todos ellos se habían realizado intervenciones arqueológicas de urgencia en los últimos veinticinco años. Es a partir de 1998 cuando todos los programas emprendidos en este sentido se aglutinaron, de forma genérica, bajo el epígrafe Ruta Arqueológica de los Pueblos Blancos (GUERRERO; COBOS, 2002: 122).

Ya en el año 2000 se amplió a un total de 19 el número de yacimientos que comprendía la ruta, más por motivos políticos que técnicos (GUERRERO

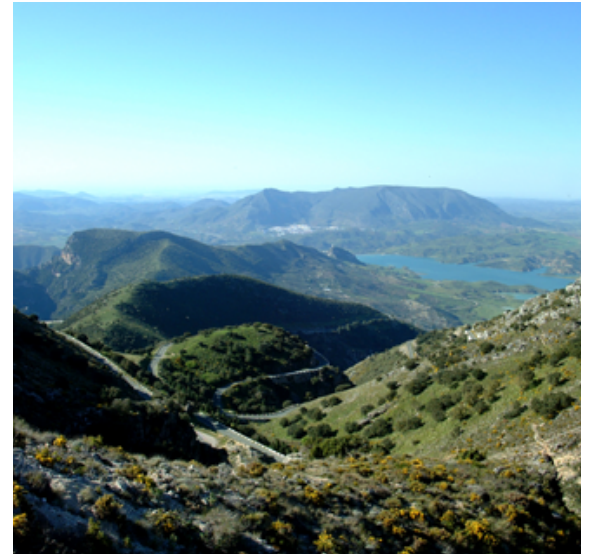

Zahara y Algodonales desde el puerto de las Palomas | foto Mancomunidad de Municipios de la Sierra de Cádiz

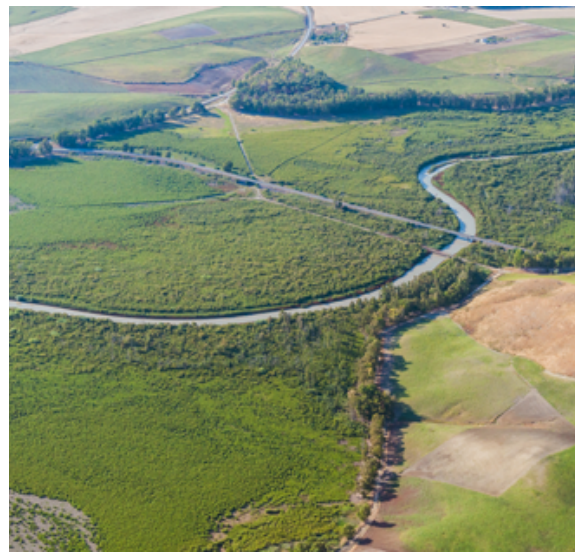

Río Guadalete a su paso por Bornos foto Manu García

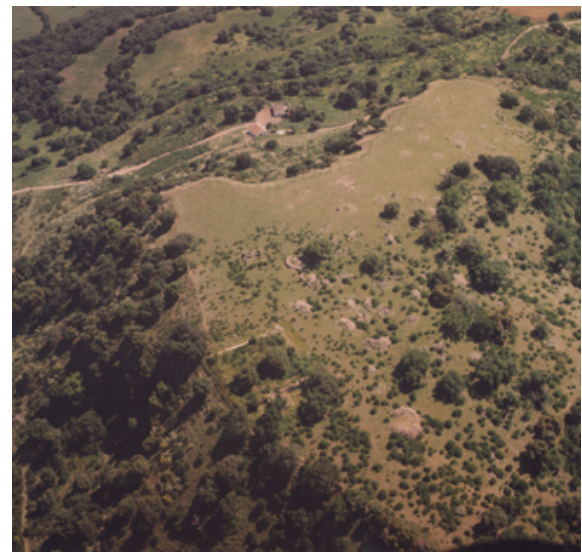

Yacimiento arqueológico de Iptuci (Prado del Rey) | foto Mancomunidad de Municipios de la Sierra de Cádiz 
MISA, 2008: 46). Ésta se dividió a su vez en tres subrutas temáticas e históricas. En primer lugar, el periodo prehistórico, incluido en la Ruta prehistórica, que estaría compuesta por el dolmen de Alberite en Villamartín, el dolmen del Charcón de El Gastor, los dólmenes de Tomillo en Alcalá del Valle y la necrópolis prehistórica de Fuente de Ramos de Puerto Serrano, conjuntos funerarios datables entre el IV y III milenio a.n.e., finales del Neolítico e inicios del Calcolítico. En segundo lugar, el periodo ibero-romano, encuadrado en la Ruta de las ciudades, con el yacimiento de sierra de Aznar en Arcos de la Frontera, Iptuci en Prado del Rey, Ocuri en Ubrique y Carissa Aurelia en Espera y el yacimiento del cerro de la Botinera en Algodonales. En tercer lugar, el periodo medieval, encuadrado en la Ruta de la frontera castellano-nazarí, en la que se incluyen la villa medieval de Zahara de la Sierra, la fortaleza de Olvera, la torre islámica y villa medieval de Setenil de las Bodegas, las murallas medievales de Torre-Alháquime, el barrio nazarí de Benaocaz y las calzadas medievales, aún transitables, de Villaluenga del Rosario y Grazalema (GUERRERO MISA; COBOS RODRÍGUEZ, 2002: 128).

Durante varios años se llevaron a cabo proyectos de diversa índole que iban configurando una visión histórica global de la Sierra de Cádiz, a través de la singularidad de cada uno de los yacimientos arqueológicos, bienes patrimoniales en general y centros de interpretación del patrimonio (históricos, etnográficos, culturales...), desarrollando un nuevo marco teórico en el que se presentaba la comarca en su conjunto como un auténtico "museo territorial" (GUERRERO MISA; COBOS RODRÍGUEZ, 2002: 122). Es en el año 2000 cuando el proyecto es denominado museo-territorio Sierra de Cádiz (GUERRERO MISA; COBOS RODRÍGUEZ, 2002: 122). Con este marco teórico se pretendía arropar conceptualmente, ya de una forma definitiva, todas las obras y acciones realizadas para la puesta en valor de los yaci-

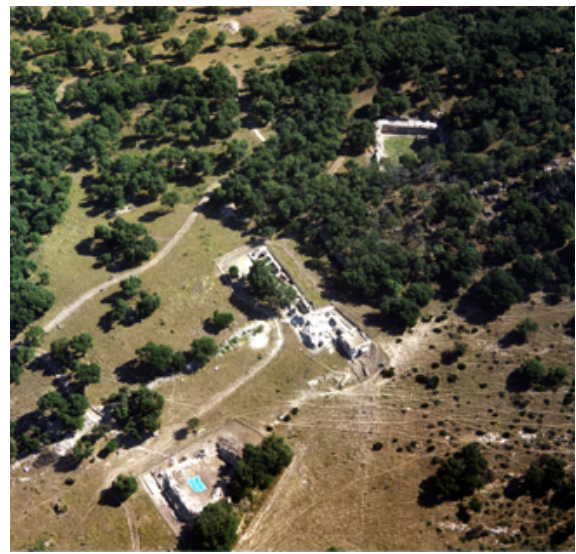

Yacimiento arqueológico de Sierra Aznar (Arcos de la Frontera) | foto Mancomunidad de Municipios de la Sierra de Cádiz

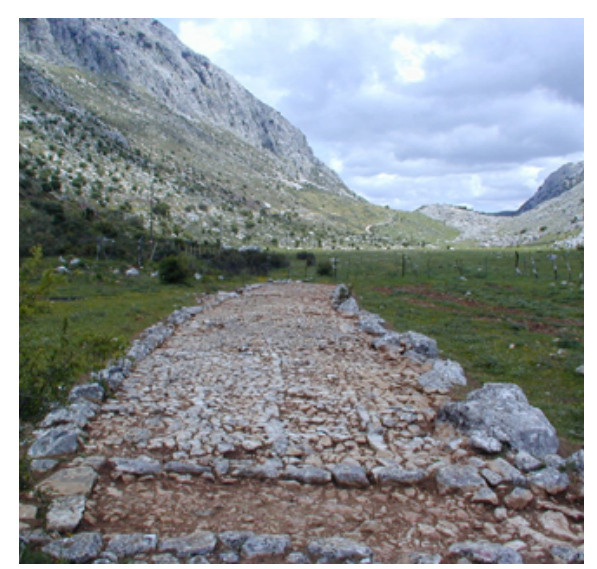

Calzada en la Manga de Villaluenga

foto Mancomunidad de Municipios de la Sierra de Cádiz

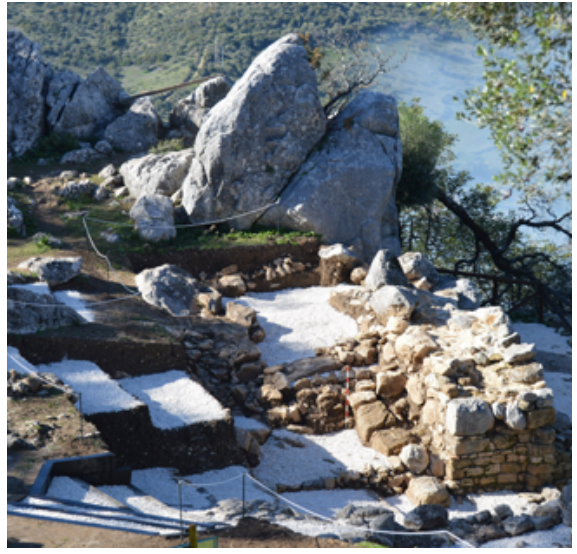

Puesta en valor del tramo de muralla ciclópea de Ocuri | foto Luis J. Guerrero 


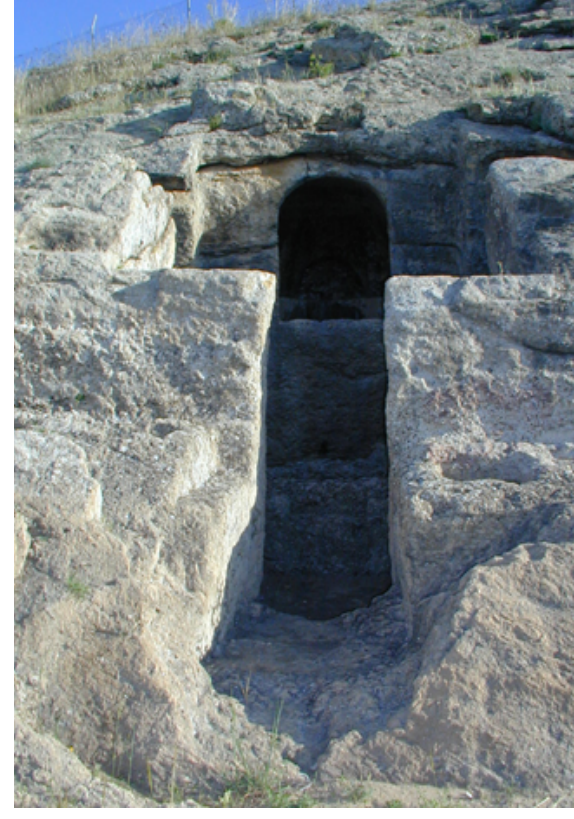

Hipogeo de Carissa Aurelia | foto Mancomunidad de Municipios de la Sierra de Cádiz mientos integrantes de la Ruta, mientras que, al mismo tiempo, se ofrecía tanto a la población local como a los visitantes, la posibilidad de disfrutar del patrimonio arqueológico y cultural de toda la sierra en una auténtica red integral turístico-cultural, convirtiéndola así en un auténtico museo al aire libre.

Este espacio musealizable comprende el patrimonio arqueológico y cultural de la Sierra de Cádiz en su globalidad, es decir, desde el entorno medioambiental y natural con sus connotaciones geográficas y bioclimáticas, hasta el conjunto básico formado por todos los restos arqueológicos e históricos que, de una $u$ otra forma, han llegado hasta nosotros.

Se apostaba, por consiguiente, por un proyecto de musealización integral del territorio, que entiende la Sierra de Cádiz como un gran "museo" al aire libre, en continua transformación, en el que debemos conservar, interpretar, mostrar y difundir nuestro rico patrimonio cultural (histórico, arqueológico, artístico, documental y etnológico) (GUERRERO MISA, 2008: 47).

El museo-territorio que se planteaba se fundamentaba en tres ámbitos: un territorio delimitado geográficamente, un patrimonio puesto en valor apoyado por las infraestructuras museísticas e interpretativas creadas (patrimonio material, inmaterial, natural y cultural) y una comunidad poblacional como agente protagonista y representante de la identidad patrimonial (GUERRERO MISA, 2008: 48).

En la actualidad la comarca de la Sierra de Cádiz presenta una red inacabada en torno al patrimonio cultural y, en particular, al patrimonio arqueológico, que constituye parcialmente ese museo-territorio referido con anterioridad. En los últimos años del proyecto se abrieron, o más bien sólo fueron inaugurados, varios centros de interpretación del patrimonio. Sin embargo, a la vez, yacimientos arqueológicos recuperados han vuelto a caer en el olvido de las administraciones. Este hecho contribuye a la percepción por parte de la ciudadanía de proyectos infructuosos, en los que ha faltado la fase de gestión y mantenimiento, la mayoría de las veces olvidada en la intervención del patrimonio. De todas formas, en la concepción teórica del proyecto se hablaba de un museo-territorio dinámico y activo. Quizás no sea éste el movimiento deseado, pero muestra la vitalidad de un recurso que se niega a desaparecer ya que numerosos visitantes recorren anualmente la comarca para conocer el territorio y sus bienes naturales y culturales más preciados y reconocidos.

Las debilidades y amenazas de hace quince o veinte años han ido modificándose a lo largo del tiempo, y las dificultades para la identificación de la diversidad arqueológica de la comarca, la escasa valoración y conciencia social de la importancia del patrimonio arqueológico, la insuficiencia de infraestructuras para su puesta en valor, o la ausencia de equipos estables de profesionales que lo gestionen, han sido superadas y sustituidas. En cam- 
bio, aparecen otros factores como la falta de planteamientos globales sobre la gestión e intervención en el patrimonio arqueológico, las escasas acciones de difusión o la falta de una política educativa patrimonial y, por supuesto, la crisis económica.

Para paliar estas fragilidades el patrimonio arqueológico de la Sierra de Cádiz posee una serie de potencialidades que ofrecen sus recursos, como son: la enorme variedad y riqueza de los restos arqueológicos; un bloque de profesionales del patrimonio cultural y arqueológico formados y disponibles; la existencia de un amplio marco jurídico en el campo del patrimonio; la posibilidad de cooperación con universidades y otros centros altamente cualificados; el interés creciente de la sociedad por el patrimonio cultural, en general, y arqueológico; el aumento del turismo cultural dentro de Andalucía y de la Sierra de Cádiz con la demanda de productos y servicios; la creciente participación de otras administraciones en la financiación del patrimonio arqueológico; y su más que posible inclusión en planes de desarrollo comarcales y europeos ${ }^{4}$.

\section{HACIA NUEVOS MODELOS DE GESTIÓN}

Es posible, por tanto, recuperar estas iniciativas patrimoniales que, junto a nuevas perspectivas, hagan posible los retos que nos propusimos hace ya más de quince años. Se trataría de articular las políticas de investigación, conservación y difusión que corresponden a la administración cultural, con otras políticas de desarrollo local o rural que se basan en la complementariedad de los recursos, tanto económicos como patrimoniales.

Es necesario un replanteamiento de lo que hoy, ya en la segunda década del siglo XXI, representa el patrimonio arqueológico y cuál es su función en nuestra sociedad, en relación con la población que lo disfruta y el territorio donde se localiza. Preguntarnos si siguen siendo útiles los planteamientos de los años noventa, cuando se inicia la democratización de la cultura en España, y si han respondido a las expectativas que se crearon en su momento sobre el patrimonio desde las perspectivas sociales y económicas.

En suma, debemos proponer estrategias que posibiliten proyectos de futuro en esos espacios patrimoniales. Para ello es imprescindible promover mecanismos que creen sinergias entre los agentes que intervienen en el patrimonio, a saber: administraciones públicas (ayuntamientos, Diputación de Cádiz y Junta de Andalucía), universidades, asociaciones de defensa del patrimonio, profesionales, sector privado, y ciudadanos en general, para que coordinen planes estratégicos de actuación ${ }^{5}$.
4

Programa de Desarrollo Rural de la Consejería de Agricultura, Pesca y Desarrollo Rural de la Junta de Andalucía y la Unión Europea. Programas con contenidos patrimoniales y vinculación estratégica al desarrollo territorial, ligado estrechamente a la valorización del patrimonio arqueológico.

5

Sería muy interesante la creación de una Mesa del Patrimonio de la Sierra de Cádiz, para la búsqueda de un modelo territorial basado en la ordenación de los bienes culturales y en su gestión. 


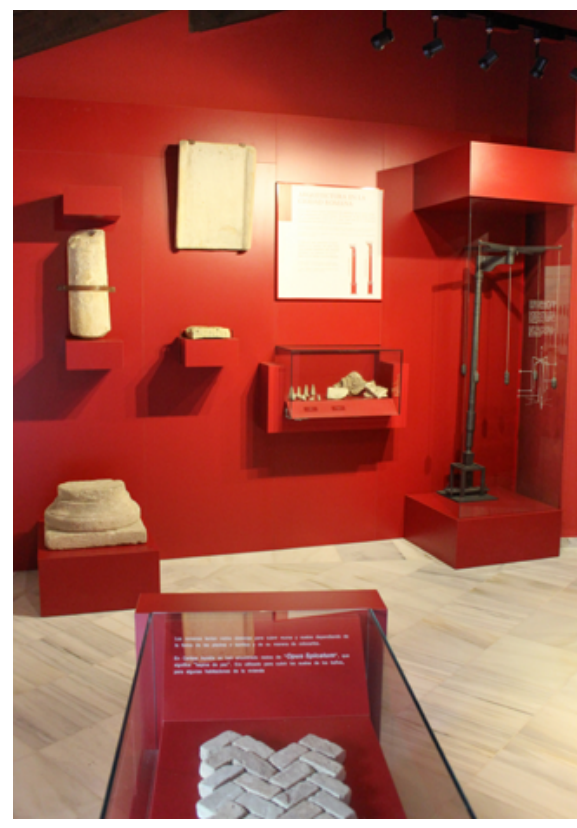

Museo Arqueológico de Espera | Pepa Lozano
Ahora bien, si existen ya modelos de gestión de los espacios culturales promovidos por la Consejería de Cultura de la Junta de Andalucía, caso de la Red de Espacios Culturales de Andalucía (RECA), sería recomendable el acercamiento de los entes municipales a los órganos competentes para la redacción de convenios bilaterales que posibiliten la inclusión en esta red del patrimonio arqueológico de la Sierra de Cádiz. Estos enclaves tienes entre sus prioridades contar con un Plan Director como instrumento de planificación y gestión a corto y medio plazo.

Igualmente puede entenderse, en virtud de la Ley 14/2007de 26 de noviembre de Patrimonio Histórico de Andalucía, que la Sierra de Cádiz pueda considerarse una de las nuevas tipologías establecidas por esta normativa en cuanto a la clasificación de bienes inmuebles. Nos referimos a las zonas patrimoniales definidas como "aquellos territorios o espacios que constituyen un conjunto patrimonial, diverso y complementario, integrado por bienes diacrónicos representativos de la evolución humana, que poseen un valor de uso y disfrute para la colectividad y, en su caso, valores paisajísticos y ambientales" (LEY 14/2007). Y para la ordenación de estos espacios, la ley misma crea la figura de parques culturales que requerirán "la constitución de un órgano de gestión en el que participen las administraciones y sectores implicados".

Es por ello que es posible recuperar la idea primigenia del museo-territorio, donde se pertenezca a un sistema integrado, unitario y normalizado que garantice su continuidad y la posibilidad de inversiones que hagan avanzar en la puesta en valor del patrimonio arqueológico. Un espacio donde cultura y naturaleza van, conjuntamente, en busca de un desarrollo sostenible, que no es otra cosa que el equilibrio entre la conservación y la puesta en valor a largo plazo de sus recursos patrimoniales. Es, en definitiva, patrimonio territorial como "parte del conjunto de recursos culturales y naturales heredados en un espacio geográfico dado, que tienen un elevado grado de aceptación y reconocimiento social" (ORTEGA, 1998: 34).

Así pues, el patrimonio arqueológico no debe desvincularse del territorio cultural de la Sierra de Cádiz, como una apuesta aislada, sino como perteneciente a una oferta más amplia y diversificada. Del mismo modo, debe fijar sus cimientos en la ciudadanía como pilar fundamental para su desarrollo. Se trataría de crear nuevos discursos con mecanismos diferentes que potenciaran la relación entre expertos y comunidad local, donde sería fundamental incorporar a personas y colectivos sociales, fuera del ambiente universitario y técnico, para una mayor implicación y participación ciudadana. Esta complicidad entre comunidad local y expertos deberá buscar fórmulas para facilitar la recuperación de un proyecto de museo-territorio de la Sierra de Cádiz donde se primen los valores educativos y el turismo cultural sostenible, siguiendo siempre buenas prácticas de uso del patrimonio. 


\section{BIBLIOGRAFÍA}

- AA.VV. (1995) Esquema Territorial de la Cuenca del Guadalete. Sevilla: Consejería de Obras Públicas y Transporte de la Junta de Andalucía, 1995. 124 p.

- CARAVACA BARROSO I.; FERNÁNDEZ SALINAS V. (2005) Patrimonio y Desarrollo Territorial. Actas de Jornadas de Patrimonio y Territorio. Sevilla: Consejería de Cultura de la Junta de Andalucía, 2005, pp. 5-18

- CATÁlogo General del Patrimonio Histórico Andaluz [en línea]. Consejería de Cultura, Junta de Andalucía, 2013 $<$ http://www.juntadeandalucia.es/cultura/web/areas/bbcc/ catalogo> [Consulta: 24/01/2016]

- COBOS RODRíGUEZ, L. M. (2003) Zahara. Memoria recuperada del Patrimonio Arqueológico. Zahara de la Sierra: Ayuntamiento de Zahara de la Sierra, 2003, 86 p.

- DECRETO de 22 de abril de 1949 sobre la Protección de Castillos Españoles, expedido por el Ministerio de Educación Nacional. Boletín Oficial del Estado, del 5 de mayo de 1949

- DECRETO 316/1984, de 18 de diciembre, de declaración del Parque Natural de la Sierra de Grazalema. Boletín Oficial de la Junta de Andalucía, n. ${ }^{\circ}$ 13, 12 de febrero 1985

- GUERRERO MISA, L. J. (2008) Desarrollo y consolidación de La Ruta Arqueológica de los Pueblos Blancos de la Sierra de Cádiz: la musealización de un territorio. En Actas de las VIII Jornadas Andaluzas de Difusión del Patrimonio Histórico (Almería, 22-24 de febrero de 2005). Sevilla: Consejería de Cultura, 2008, pp. 43-57

- GUERRERO MISA L. J.; COBOS RODRÍGUEZ L. M. (2002) La Ruta Arqueológica de los Pueblos Blancos de la Sierra de Cádiz: Una apuesta por el desarrollo económico y social basada en el Patrimonio. En SÁNCHEZ DE LAS HERAS, C. (coord.) Actas VI Jornadas de Difusión del Patrimonio. Sevilla: Consejería de Cultura de la Junta de Andalucía, 2002, pp. 121-138

- LEY 2/1989 de 18 de julio, por la que se aprueba el inventario de Espacios Naturales Protegidos de Andalucía y se establecen medidas adicionales para su protección. Aprobada por el Pleno del Parlamento los días 27 y 28 de junio de 1989. Boletín Oficial de la Junta de Andalucía, n. ${ }^{\circ}$ 60, de 27 de julio de 1989

- LEY $14 / 2007$ de 26 de noviembre de Patrimonio Histórico de Andalucía, en sesión celebrada los días 14 y 15 de noviembre de 2007. Boletín Oficial de la Junta de Andalucía, n. ${ }^{\circ}$ 248, de 19 de diciembre de 2007 (arts. 26.8 y 81)

- ORTEGA, J. (1998) El patrimonio territorial: el territorio como recurso territorial y económico. Revista Ciudades, n. ${ }^{\circ}$ 4, Territorio y Patrimonio. Valladolid: Instituto Universitario de Urbanística de la Universidad de Valladolid, 1998, pp. 33-48 